\title{
11
}

\section{REFRAMING SUSTAINABILITY CHALLENGES}

\author{
Fiona Marshall, Patrick Van Zwanenberg, Hallie Eakin, \\ Lakshmi Charli-Joseph, Adrian Ely, Anabel Marin, and J. \\ Mario Siqueiros-García
}

\section{What is 'framing'?}

Ideas are powerful. Whether in the form of values, preferences or beliefs about how the physical and social world works, they enable people to make sense of complex socio-physical realities; to identify and prioritise problems, understand why they arise, and articulate the kinds of responses that are desirable and feasible. Ideas, as much as material interests, or command over resources, help to structure and shape collective action.

The concept of framing was described by Goffman (1974) as a cognitive process through which people make sense of events and experiences. In the context of contested sustainability challenges, it is useful to refer to framings as the ideas (in the form of assumptions, interpretations and values) that people bring to a particular issue; shaping how and for whom issues are seen as problematic, and how issues are explained. A particular framing implies a structure and stability to the conceptualisation of an issue (Laws and Rein, 2003), and a focus on the ideas within the frame, to the exclusion of those outside it. For any given issue, there may be multiple contested framings. These framings give rise to empirically observable narratives, or stories, about an issue, problems associated with it, potential consequences and how they can be addressed (Hajer, 1995; Roe, 1994). The interplay between competing narratives is shaped by both power and politics. Powerful institutions have more resources with which to assert the narratives to which they ascribe; specific agendas and social positions are reinforced and enhanced by the dissemination of specific issue frames. Thus, analysis of narratives is useful for revealing underlying framings, and the interplay between narratives can reveal much about the enactment of power.

In the context of research into transformations to sustainability, attention to framings and their associated narratives can provide useful insights into how

DOI: $10.4324 / 9780429331930-15$ 
system change evolves (see Chapter 3). In transdisciplinary action research, engaging with and influencing framings and narratives with a diversity of actors associated with a specific problem domain can be fundamental to the theory and practice of contributions to transformative change.

Framing and reframing of problem domains and solution strategies played diverse but central roles in the transformative initiatives described in this volume. Framing/reframing in these initiatives was both an element we observed as part of the socio-technical-environmental processes we engaged in, and a tool we mobilised with our partners as part of processes of transformation. In this chapter, we introduce framing as a central concept to our work in transformation, and illustrate how it was manifest in the diversity of projects we were engaged in.

\section{Framing and reframing in STEPS Centre work}

Work within the STEPS Centre has an established tradition of seeking to understand different peoples' "framings and their associated narratives concerning the functions and dynamics of particular socio-technical-ecological systems, and the nature of sustainability problems that those systems give rise to" (Leach et al., 2010a). The Centre has examined how different framings lead to sets of narratives about who ought to act on those problems and how, and what count as solutions. It has investigated how certain narratives of sustainability gain attention and are pursued, while others are neglected or ignored (Leach et al., 2010b), exploring the politics involved in choosing and pursuing some variants of sustainability rather than others. The studies demonstrated that, in policy contexts, narratives that appear to reduce uncertainty tend to be favoured and become dominant, even if they are inaccurate, perhaps because they can lead to clearer plans for action (Roe, 1994). They also demonstrated that as strategies develop for interventions based on these dominant narratives, system change develops around them, further marginalising the alternatives (Leach et al. 2010a).

For example, Cavicchi and Ely (2016) describe how dominant narratives framed agricultural, economic and energy challenges in the Emilia Romagna region of Italy, in a way that led to particular pathways of bioenergy development from 2000 onwards. These focussed on large (national/regional)-scale initiatives which responded to industrialisation and energy security concerns to the neglect of smaller scale biogas plants that responded to local needs. They also explored how alternative framings (held by farmers and communities and prioritising the local environment and economy) emerged as a result of material system changes such as increasing environmental impacts of large-scale operations and changes in land prices and became amplified over time.

The ambition of STEPS work has often been to help widen appreciation of alternative framings and pathways to sustainability visions, particularly by helping to make visible the ideas of groups of people who are marginal to formal political processes. In relation to transformation, the premise is that dominant problem and solution frames can lock-in pathways of development and change. This rigidity results in path dependency and the persistence of undesirable and often unjust 
system states (Stirling et al., 2007; Stirling 2012). The emphasis of the work has not been to promote one particular alternative framing but to bring more options to the table (broadening out the types of knowledge and innovation options that are considered and opening up a range of possibilities for solutions) (ibid).

For example, Randhawa and Marshall (2014) and Randhawa et al. (2020) examined the interplay between contested framings of water and waste management challenges in peri-urban Delhi. They examined the adverse implications of the dominant narratives and their associated policy and interventions from the perspective of local communities; in terms of social fragmentation of basic service provision, environmental health threats and livelihoods. The transdisciplinary research team highlighted possibilities for a reframing of key issues in water and waste management through a sustainability lens. In doing so they helped to bring together the perspectives of groups that had been challenging the dominant narrative on the basis of lack of attention either to social justice or to environmental concerns - but through divergent, rather than convergent framings and strategies. Reframing through a sustainability lens emphasised the complex realities of social-material flows of water and waste. It led to a focus on adaptive, decentralised approaches to waste and water management policy and practice, including possibilities for constructive engagements between the formal and informal sectors and the need for a diversity of technologies and innovation pathways which address social justice and environmental concerns in integrated and complementary ways (Randhawa and Marshall 2014; Randhawa et al. 2020).

In another example of STEPS work, van Zwanenberg et al. (2011) examined the different ways in which international agencies with responsibility for regulating transgenic crops (national regulators in China and Argentina, and local officials in those countries) framed both the purpose of transgenic crop regulation and the object of control (that is the components of the socio-technical practices that were assumed to require regulation). These framings were then contrasted with small farmers' experiences of how transgenic seeds are obtained and used, and their understandings of the problems that this entailed. The study revealed how, in both cases, small farmers' circumstances and interests fall at least partially outside of both national and local framings of the problems posed by transgenic crops and of the relevant socio-technical practices. It showed how the actual use of transgenic crops in particular localities in Argentina and China bore little resemblance to how its controlled use is framed in international norms. The study argued that regulations that better address realities on the ground, and that manage to support rather than undermine smaller farmers' livelihoods, imply that national and international understandings of regulatory purposes and the systems requiring control would need to be rethought.

\section{Reframing in the 'Pathways' transformative knowledge network}

The 'Pathways' transformative knowledge network (TKN) shared the ambition of earlier STEPS work to understand the evolution of different issue/problem framings and their implications for policy development and practice. The 
network also retains a focus on potential emergent pathways to sustainability that reflect the framings of previously marginalised groups of people; a manifestation of the centre's core normative commitment to progressive social change. But, while many of the previous STEPS initiatives had sought to work with stakeholders to widen appreciation of possible alternative framings and visions of alternative future pathways of change, the 'Pathways' network sought to push the concept of framing further in the context of efforts of intentional transformation. As a transformative knowledge network we sought to enhance understanding of the dynamics and drivers of sustainability transformations, but also to work as scholar-activists to contribute to transformations in particular contexts, engaging actively as transdisciplinary teams in aspects of the creation and enabling of alternative pathways of change (see Chapters 3 and 4).

Underpinning this approach is a particular type of interdisciplinarity in which diverse stakeholders were 'recognising together how problems are perceived differently - listening and acting' (Allouche et al., 2019). This should be distinguished from a passive listening to the perspectives of others. The teams actively considered how and why sustainability challenges look entirely different depending on the perspective from which they are viewed, recognising the social interactions and politics of knowledge that impact on that perspective.

As we explained in an earlier publication

The 'Pathways' network involves a wide range of disciplinary perspectives including development studies and science and technology studies. It engages diverse sets of actors in participatory processes to explore alternative framings of problems, and novel ideas for moving towards more just and sustainable configurations of socio-technical-ecological systems. More metaphorically, the Pathways network is honing in on the "wavelength" of the politics of knowledge, and in particular the social interactions that enable alternative, more sustainable directions of change to be realized. This includes both the processes through which possibilities for alternative trajectories of change become recognized, and through which they are able to gain traction.

(van Zwanenberg et al., 2017)

As discussed in Chapters 2 and 3 and later in Chapter 12, these activities of the 'Pathways' network can be described in terms of 'enabling' approaches to transformations (Scoones et al., 2020), which tend to challenge incumbent interests and control, emphasising political mobilisation and emancipation.

Team members recognised and reflected on their own roles as scholar activists. The roles rarely involved confrontational approaches in which incumbent interests and control were directly challenged. The range of strategies to enable transformations included the legitimisation of alternative perspectives, enhancement of the agency of marginalised groups and alliance building which led to the recognition across previously divergent interest groups of the potential mutual 
benefits of realising alternative pathways (Charli-Joseph et al., 2018; Eakin et al., 2019; Marshall et al., 2018; Pereira et al., 2020).

In thinking together across the 'Pathways' network about how possible alternative pathways are recognised and how they gain traction in practice and policy, we have become increasingly interested in processes of reframing. Understanding how, for example, a policy community's understanding of a sustainability challenge, and the actors and processes assumed to be central to trying to address that challenge, can be effectively shifted, thereby bringing alternatives into active consideration. Or how communities whose livelihoods are adversely affected by a dominant change trajectory can change their perspective concerning potential drivers of change such that their own collective agency to support transformative processes is recognised and enhanced.

\section{Reframing and articulation of processes of transformative change}

Drawing on some of the case studies described earlier in this book, we discuss a number of different ways in which reframing played a role in theories of transformative change across the network, and in the associated T-Lab activities in different contexts.

\section{Theory of change}

Each of the 'Pathways' projects began with a problem definition and an articulation of a desired transformative system change. Much of the overall desired system change was beyond the scope and agency of the individual hub projects, but the teams articulated the aims of their projects, in terms of what they would contribute towards processes of transformative system change, and how this would be achieved. This articulation formed the starting point for a theory of change (ToC) for each of the projects, which evolved throughout all phases of a project, and beyond. A ToC describes what needs to change and how, in order to meet the aims of the project, and what assumptions underpin the change processes that are articulated - but it can take many forms (Oberlack et al., 2019; Vogel, 2012). As trajectories of social, technical and environmental change unfold in the complex dynamic contexts in which the 'Pathways' hub teams worked, assumptions were challenged and new possibilities for influence emerged, while others closed down. Thus, revisiting the ToC, helped to support collaborative and iterative processes of reflection and engagement on how change occurs and what influence is feasible in particular contexts; thereby leading to amendments and guiding future interventions and initiatives.

ToC can take many forms, but will often specify how a research team considers which stakeholders' understandings, attitudes, skills and behaviours need to change, and in what way(s), in order to achieve a desired set of outcomes (Vogel, 2012), and furthermore what activities of the project will help enable 


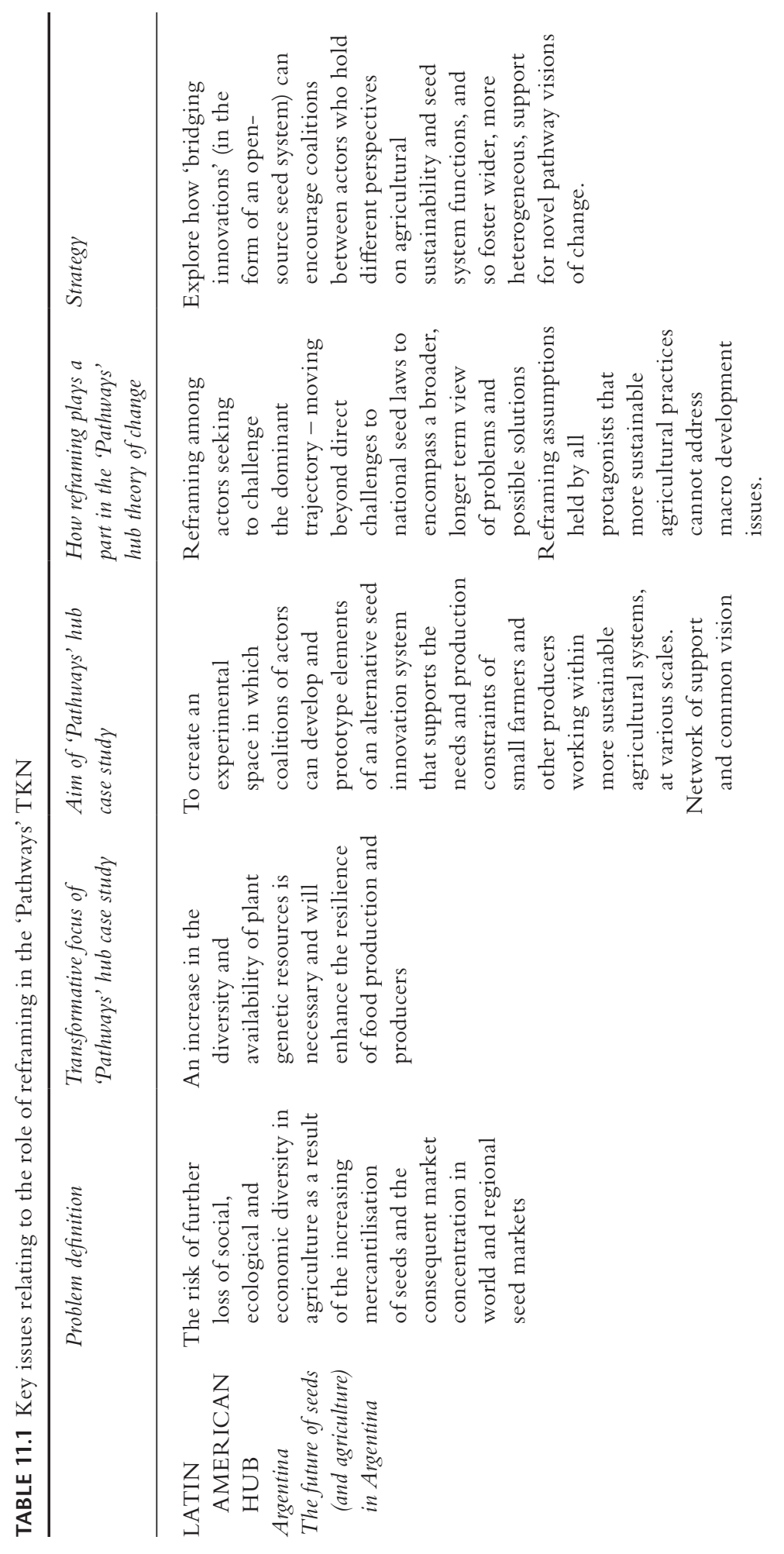




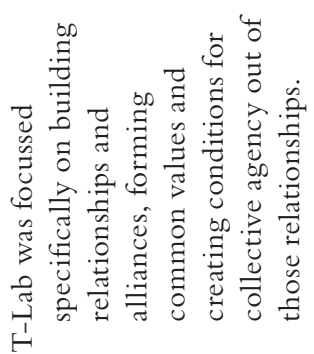

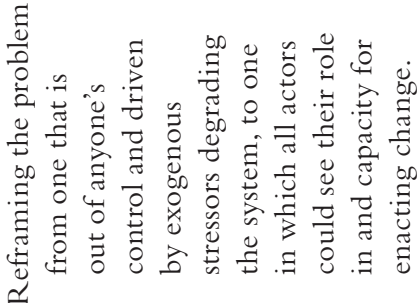

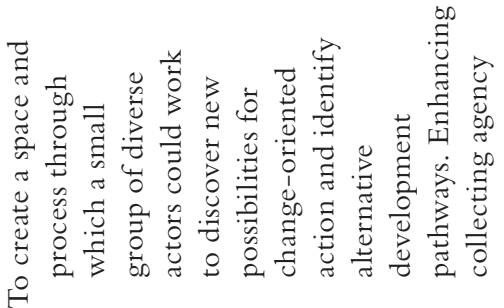

8

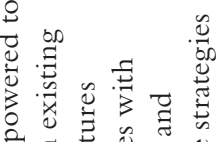

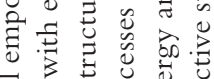

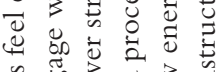

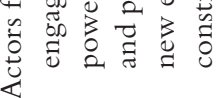

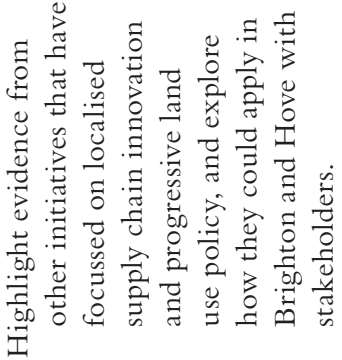

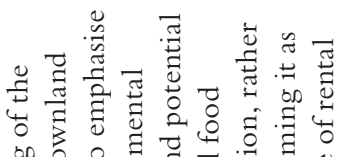

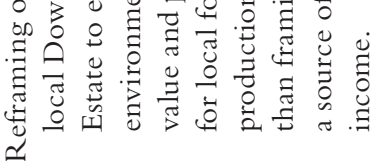
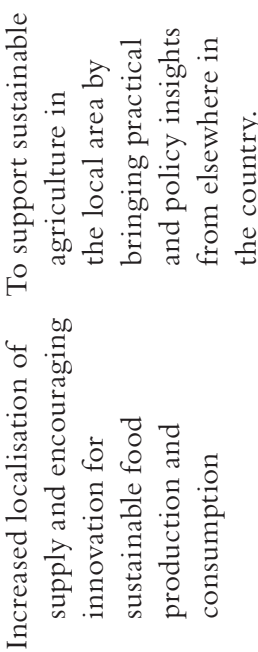

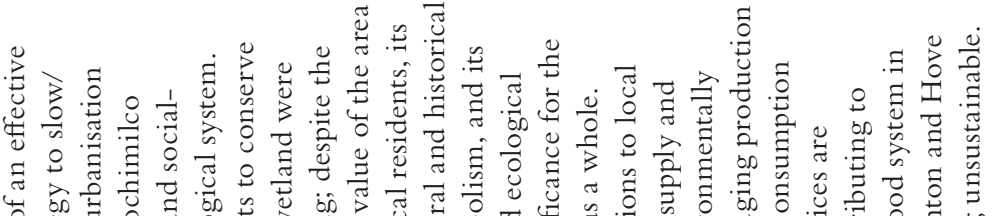
फ

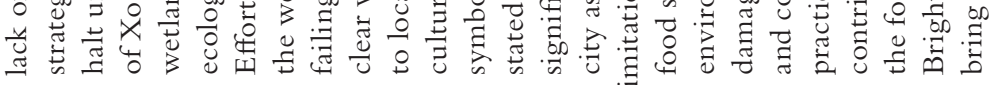

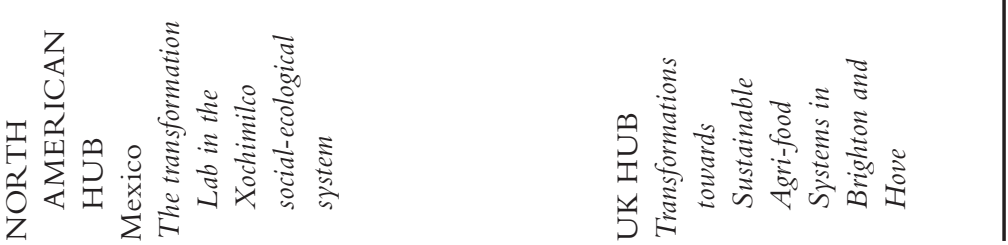


those changes, and in what ways, and based on what assumptions. The notion of reframing fits well into this approach to a theory of change. In relation to this, as part of the final survey (December 2018), each of the 'Pathways' case study teams were asked to consider the following questions:

a In what ways and at what levels (individuals or groups at different scales) did a reframing of problems/issues/debates play a role in the theory of change?

b How do we understand reframing in terms of its potential contribution to a wider process of transformative change?

c How did the team seek to engage with framing/reframing and what was learnt (about processes and methods)?

d What, if anything, emerged unplanned as an identified need for reframing as a result of the project process? (reflective of the need to revisit a ToC)

Key issues relating to the role of reframing in the 'Pathways' hubs' theories of transformative change are summarised in Table 11.1. This table begins with a summary of the overall problem definition, followed by the aspects of required system transformation that are the focus of the initiative. This is followed by an articulation of the aim of the transdisciplinary research project itself, the role of reframing within the ToC and the strategy to engage with and influence reframing processes.

\section{Reframing processes}

From the illustrations above we can characterise a number of different types of interacting reframing processes and lessons relating to them.

The Argentine case study was concerned with how different actors frame the sustainability challenges associated with market concentration and strict intellectual property rights (IPR) and potential solutions; it demonstrates the role of transdisciplinary research in at least three different types of, mutually reinforcing, reframing processes.

Reframing to expand understanding of what constitutes a system and the feedbacks and trade-offs involved.

This initiative attempted to broaden and enrich existing conversations about IPR and the seed sector, to illuminate the long-term sustainability challenges and therefore open up a dialogue about the importance and significance of alternative pathways. At the start of the project many of the participants in the deliberative process focussed on the immediate conflicts over seed IPR between issues of seed price and access for farmers versus ability of overseas firms to capture innovation rents. The idea was to broaden the problem framing, which had so far focussed on resistance to plans to tighten seed IPR, and incorporate longer term and more hypothetical, but still likely, effects of strict IPRs. These included effects on rural 
socio-economic and crop diversity, industry structure and economic development, such that the inclusive development and ecological sustainability elements of alternative seed and agricultural systems were apparent. This reframing within the team itself, and the networks of actors with whom the team were engaged, was a precursor to the wider engagement activities that followed. The time horizon in thinking about IPR and the seed sector was an important element in how this reframing process was undertaken. Many of the possible problematic implications of strict IPRs that we wanted our team and wider networks to think about are not yet apparent, or there are only indications so far of how they might impact on agricultural systems. Bringing in experience from other countries, where stricter IPRs are more established, was an important means of fostering that longer term and broader perspective.

Reframing of value (what matters and how it matters): building the legitimacy of marginalised knowledge

In the process of conducting the project the desirability of reframing certain issues, which had previously been unanticipated also became apparent. For example, it became apparent that activists campaigning for more diverse, smaller scale and less intensive alternatives generally do not address, or do not have a view about, broader macro level issues - for instance, about how such alternatives could become a means of economic growth, development and diversification, or how exports could be sustained through alternative practices. Partly for this reason, they tend to be ignored, or dismissed as naïve by other actors concerned with the critical macro-economic role of agriculture. So here, the team recognised the importance to "reframe" taken-for-granted assumptions, namely that more sustainable agricultural practice cannot address macro development issues, such as the need to diversify productive activity, or to build new export markets. This reframing process is recognised as a long term objective and based on an ongoing process of alliance building and dialogue which occurs in parallel to the other activities of the team. The nature of this reframing challenge is exemplified in the fact that mainstream policy institutions currently view support for practices such as agro-ecological production primarily as a matter of social welfare policy (to support communities who find themselves marginalised from mainstream economic activity) rather than one of agricultural innovation per se.

Reframing of solutions: the possibilities for divergent interests to come together in alternative pathways

Finally, a key reframing activity stemmed from the team's interest in innovations that could bridge different perspectives on sustainability, demonstrating that there were often mutual benefits of seeking an alternative pathway of change for previously diverse interest groups. The idea was that certain innovations (such as open-source seed licenses) might find sufficient support both among stakeholders 
concerned primarily with issues such as food sovereignty, local production and small farmers livelihoods, and those concerned primarily with the macro issue of sustaining the role of the agricultural sector, through continued innovation. Might such an innovation prompt stakeholders to appreciate or reinterpret their interests and perspectives in slightly different ways (for example, on the one hand, rural social movements traditionally opposed to any seed IPR whatsoever, but who might see how a protected commons could ensure continued seed access, and on the other hand, domestic seed firms who work within an opensource logic already, but would not be able to compete if patents became more widespread for seeds)? An interesting issue for the research team was how the process of trying to innovate, that is of trying to do new things - or old things in new ways - is by definition a way of thinking about solutions in novel ways, and this also tends to prompt new ways of thinking about issues and problems. Innovation and reframing are thus tightly linked, with causation running in both directions. This type of 'bridging innovation' approach may be particularly effective where there is a possibility to develop alternative pathway visions and to demonstrate the material benefits of them to multiple, kinds of actors and organisations. In developing and engaging an increasing number of people in these bridging innovations (Ely and Marin, 2016), the other reframing objectives are also being simultaneously addressed.

\section{The North American Hub}

The Mexico case, focussed on the degradation of the Xochimilco wetland in Mexico City, engaged directly with reframing as a central component of the ToC adopted by the team. In the Mexican T-Lab, reframing was a deliberate strategy to enhance the collective agency of stakeholders, thereby helping to recognise and realise new possibilities for action. While no particular social innovation was imagined for the T-Lab, the team hypothesised that working with diverse actors in the wetland context could lead to alternative framing of the problems they confronted. The ToC embraced the view that reframing could contribute to breaking cognitive pathways and the mental models that limit one's ability to imagine solution possibilities. Such reframing would potentially enhance opportunities for individual and collective agency. Reframing thus was a core component of the engagement strategy, and an explicit and transparent part of the dialogues held with participants in the T-Lab process. Over the course of the two years, reframing was evident in the same core dimensions as identified in the case of Argentina as follows:

Reframing Value: Reframing the social-ecological system as a "spiderweb" of shared values and meanings

As with problem domains characterised by ecological disruptions and environmental degradation, much of the focus in prior efforts to sustain the 
Xochimilco wetland had been in terms of collecting environmental data (water quality, biodiversity, land use, etc.), and in documenting the steady advance of informal settlements over the wetland ecosystem. As a result, the dominant framing of the problem focussed on ecological dynamics and "irregular/illegal" (and anonymous) settlers as the primary driver of change; the specific activities, decisions, emotions and relationships of those who lived within and around the wetlands were lacking in this narrative. One of the primary T-Lab activities was to re-situate the individual participants within the Xochimilco system by depicting their actions and their social relations as core dynamics within the broader social-ecological system (i.e. through methods such as Agency Network Analysis, see Charli-Joseph et al., 2018). In collective activities, participants identified the material objects and landmarks that were meaningful to them in the system, and then shifted their focus to make those meanings and values explicit. In this way, they reframed the system not as one of, for example, soils, water, farming implements, fish and tourists but rather one of, for example, autonomy, self-reliance, belonging, beauty, independence. This process situated each actor, regardless of his or her role and activities in the system, as connected through a "spider-web" of shared meanings that then became the basis for a shared identity for the T-Lab group and thus a reframing of the objective for sustainability. Rather than focussing exclusively on sustaining specific material conditions and realities, the group also recognised the importance of sustaining the values and meanings that these material conditions gave rise to.

Reframing of problem and system elements: towards enhanced responsibility, empathy and solidarity.

One of the most significant processes of reframing was in relation to the dominant narrative of what the central problem was that needed to be addressed. The actors in the T-Lab, including the researchers, initially saw the problem as one of ecological degradation caused by urban encroachment by informal and illegal settlements. Through a series of different activities designed to foster reflection and sharing of perspectives, including Q method, open discussions, the "Pathways Game" and other activities (see Ruizpalacios et al., 2019), we noted that the dominant narrative shifted. Participants began to see their own responsibility for the problems they confronted, and saw that the problems were not just external but also internal, related to the attitudes, values and perspectives of their children, the farmers in the wetland, as well as urban residents. We observed the use of phrases in the group such as "We need to change the chip!", referring to the need to change their own narratives about the problem, rather than demanding that others change their behaviour and actions. The September 2017 earthquake, which destroyed many of the informal houses that had encroached on the wetland, also generated a sense of empathy and solidarity. By the end of the T-Lab process, the narratives the participants adopted had more to do with 
metaphorical "building bridges" across different users of the wetland than blaming external "others" for the lack of progress in solving the critical challenges they faced.

Reframing solutions: reframing the role of the researcher as both convener and instigator of solution pathways

Another critical domain of "reframing" was through the ways in which the different participants in the T-Lab perceived their role, and the role of others, in catalysing change. While the TDR team served the critical role of convener, sponsor and organiser of the T-Lab process, the team stressed from the start the desire for the project to be collaboratively shaped and driven forward. In essence, the transdisciplinary aim of the project required reframing the role of the research team from its traditional role of collecting, collating and disseminating knowledge to one of convening, facilitating and creating spaces for sharing and reflecting understanding. For non-academic participants, this meant embracing a novel conceptualisation of "research" and the role of academic partners. For the researchers, this meant intentionally taking a back seat and letting the interests of the participants direct the evolution of the project, while also being willing to put the specific capacities and skills of academia at the service of the T-Lab group.

\section{The UK Hub}

Reframing of system elements and boundaries: changing understandings of the city's 'agri-food system'

The framing of the research, and the discussions and engagements associated with it, evolved as the project progressed. At the co-design workshop, one perspective was that there was no 'agri-food system' in Brighton and Hove, because such an overwhelming proportion of the food consumed by the city is produced elsewhere. This was challenged when the transdisciplinary research team decided to look beyond the city at the surrounding area, broadening the framing of the system to (initially) include a $50 \mathrm{~km}$ radius in their studies. Later the system boundaries were reframed to extend no further than the Downland Estate, as described below.

Reframing the problem focus around centres of responsibility and governance

While the hub's work started out by identifying a broad problem 'space' (in a non-geographical sense), this changed over the four-year period of engagement and the key reframing aspects of the work emerged only in the late stages. 
Initial research interviews following the co-design workshop and the discussions at the first T-Lab workshop began to explore and highlight two areas as key interventions:

- $\quad$ strengthening market linkages via supply chain innovation and

- changes in land use policy to support new entrant agro-ecological farmers

This second area became the primary focus of ongoing research and engagement work in the latter part of the project, on the basis of inputs from local producers and retailers who felt marginalised in mainstream debates. Rather than a blanket $50 \mathrm{~km}$ radius (which had been used as the sampling field for the earlier interviews) or the Brighton and Lewes Downs Biosphere (a UNESCOrecognised area spanning Brighton and Hove and neighbouring local authority areas and delineated by two rivers), a specific focus on the Downland Estate was adopted. This was the area owned by the Brighton and Hove City Council, thus aligning the research focus with a specific governing actor (or constellation of actors around the local authority). This shift in focus took place against a background of public mobilisation in opposition to the local authority selling off areas of publicly owned farmland (the Downland Estate, which was framed by the local authority at least partially as a source of income through rental or sale to pay for local services amidst dwindling budgets) (Brighton Argus, 2016; 2017).

\section{Reframing value of the Downland Estate around food and ecosystem services}

Subsequent research investigated the potential for local agro-ecological food production on the Downland Estate, its relevance to issues of biodiversity conservation and local food poverty, and reframed the publicly owned land on the basis of its environmental value and potential contribution to a sustainable food system. These insights were discussed in depth at the second T-Lab workshop, when mainstream groups (including statutory authorities and local land agents) were brought together with more marginal groups (including landless agricultural producers and community campaigners) to explore innovative approaches to using the Downland Estate. At the time of writing (January 2020), the hub team cannot claim to have seen a broader reframing of the role of the Downland Estate by wider societal actors (in particular the City Council); however there is evidence of other activities that resonate with our work. Elements of the discussions at the second T-Lab workshop are being experimented with by nearby farmers (for example, High Barn Farm in nearby Rottingdean established a crowd-funding campaign in 2019 to set up an agro-ecological communitysupported agriculture initiative). Elements of the discussions in the same T-Lab workshop have also been included in community consultations around Brighton and Hove's food system to 2030, with key themes including "better 
use of land assets" (Brighton \& Hove 2030 Vision). The extent to which these will translate to wider systemic change over this same timeframe remains to be seen.

Reframing of solutions: looking beyond project-based interventions to longer-term transformations

In engaging with a wider range of actors, the initial project interest in local food production gave way to a recognition that the Downland Estate, and its multiple benefits, were themselves subject to different understandings and prioritisation. Rather than any particular solution being driven (or even advocated) by the research team, one of the key suggestions that arose in the July 2018 workshop was that a democratic/participatory process was needed to consider the wider role of the Downland Estate, and that a clear vision and political leadership was required to take it forward and implement a new approach to managing the Estate. The workshop also surfaced unanswered questions around a more fine-grained understanding of the potential for food production and a need for continued experimentation around agro-ecological approaches and other forms of innovation (including tenancy agreements, logistics and distribution, business models). Within the broader context of change in UK agriculture following the departure of the UK from the European Union, the research highlighted opportunities for Brighton and Hove "to value and reward its tenant farmers for the environmental contributions they make, and to ensure these are not eroded in the face of growing uncertainties" (Ely and Wach, 2018). Precisely how to do this was a question for the wider community, in which the T-Lab had made an important contribution.

\section{Learning across the TKN: what was reframed, and how?}

Through different approaches to reframing, each of the hub initiatives aimed, in various ways, to impact the ways that sustainable development issues were perceived. Through reframing, the initiatives managed to create spaces where assumptions could be questioned, deliberated, and reconstructed. The examples above highlight four distinct, but interacting, processes of reframing: 1) reframing of the nature of a problem, its scope and consequences - involves changes in understanding of what constitutes a system and the synergies and trade-offs involved in different development trajectories, 2) reframing of what is of value in the system and what is valued by whom, 3) reframing of ideas concerning the forms a 'solution' might take and 4) reframing of who does what in relation to transformative change and where agency and responsibility reside.

Across the Pathways network it was clear that if reframing is embraced as a strategy and process of transformative change, there is a need to make explicit the point of departure: i.e. What are the initial frames of problems, relationships and solution pathways? What interests and agendas are associated with such frames, 
and what responsibilities do they imply? Making such initial framings explicit allows collaborators in an initiative to evaluate how their thinking has changed over time, why, and what this means for their own work moving forward. It also focusses attention on the politics of knowledge and associated power relations, allowing all participants, including researchers, to 'step outside of themselves' and see how their thinking, and the thinking of those around them, is shaped by the interests and agendas of powerful actors.

In all cases, reframing also engaged with the question of "what matters". This was an intentional effort in the Mexican case, resulting in a shift in thinking about the shared underlying values that the wetland system represented to participants. In the Argentine and UK case, reframing entailed recognition of alternative, previously marginalised perspectives and the promotion of these perspectives and activities as valuable elements in the transformations being considered; thereby opening up the types of 'solution' that were possible. Across the TKN the idea of 'putting the solutions into practice' was understood broadly in terms of the means of unlocking the potential for a more plural range of solutions/interventions.

Reframing was also evident in expanding ideas about cause-effect interactions and the agency and responsibility of specific actors. This was particularly evident in Mexico, where the activities and methodology deployed in the transdisciplinary research process were designed to elicit reflection on individual and collective agency, and was instrumental in shifting participants' focus inward to their own actions and capacities, rather than "blaming" others for the challenges they confronted (Eakin et al., 2019).

In all three cases, the core research teams, who acted as both investigators and subjects of investigation (with a diversity of roles encompassing those described by Wittmayer and Shäpke (2014) as change agents, knowledge brokers, reflective scientists, self-reflexive scientists and process facilitators) also reframed their own understanding of what the interaction of researchers and non-academic collaborators could or should be. This was notable in the Mexican case, where many of the participants in the T-Lab had previously experienced interactions with academic partners that had resulted in frustration and low expectations. While such engagements had been less than productive, alternative forms of co-production and collaboration were novel and required reframing what such engagement could be.

In all three of the cases described above, reframing was an emergent outcome of the transdisciplinary research process, occurring concurrently with processes of social learning, discussion and exchange of alternative perspectives on the issues at hand. For example, while reframing was not an explicit part of the ToC articulated in the UK case, as participants in the process learnt of the local government's actions to sell off farmland, the focus of the problem domain shifted and became more focussed. In the Argentinian case, the transdisciplinary research team intentionally introduced insights from other parts of the world where seed property rights were in contention and connected alternative farming and 
seed breeding practices to the debates at the national and international levels. By revisiting their Theories of Change, the teams could support collaborative and iterative processes of reflection and engagement with non-academic participants on how change occurs and can be influenced in particular contexts. This reflective process allowed the teams to amend and guide subsequent actions, to help enable the potential for synergies to evolve. In the UK case the research focus was amended so much that by three years into the process the team were largely working with a set of issues which had been unanticipated at the outset.

\section{The interplay between reframing, alliance building and innovation}

Reframing enables looking at the world in a different way, recognising alternative - often marginalised - perspectives and rethinking core issues of value, responsibility and agency. Reframing can thus be considered a part of social learning processes, and a key part of building alliances across seemingly oppositional groups (Marshall et al. 2018; Page et al. 2016; Pahl-Wostl et al. 2008). As shared values are discovered, and alternative perspectives are evaluated in participatory contexts, conditions can be created for new alliances across disparate groups of actors. Reframing thus works iteratively with alliance building, helping create and reinforce bridging capital. This was observed in the Mexican case, where a growing appreciation among the participants emerged for the livelihood predicaments of both primary producers in the wetland and the informal settlers who were gradually encroaching on the wetland ecosystem. By the end of the process, the participants were discussing what interventions might serve to build figurative bridges to connect the disparate actors in the area. In the UK case, reframing was leading to an initiation of discussions over future land use between landless farmers and community members, and the local statutory authorities and land owners.

The case studies also cast light on the interplay between reframing and innovation, with innovation used to support reframing, and reframing leading to further innovations in support of sustainability transformations. The attention of each of the pathways hubs on novel solutions is in itself a reframing of how to respond to challenges, and how such solutions might be brought into practice (who has agency, what do they need to do to make something new happen, how to convince others that the idea is worth supporting and pursuing, which also involves a kind of reframing process too). This causality runs in both directions, because the effort of trying to do something novel or get a novel practice underway is a vehicle for helping to think in different ways about the problem, or at least directing attention on the need to do so.

For example, the Argentinian hub focussed on 'bridging innovations' that led to reframing and to the building of alliances across diverse interest groups in support of more plural pathways. The open-source tomatoes promoted in this case (see Chapter 6 this volume) attracted a lot of attention within the plant breeding community and the media, which helped to open up a discussion with 
new actors about what is problematic about a seed industry which is controlled by just a handful of firms. The innovation - the open-source tomatoes promoted through the seed breeding platform - generated and contributed to a longer term process of reframing sustainability problems and their causes.

Trying to do something new also throws into focus particular kinds of problems or barriers to change. Such barriers also need to be thought about in different ways if they are to be overcome, demanding innovation. In the Argentine case, such innovation entailed trying to make collaborative breeding work in maize explicit to address the cognitive barriers faced by both farmers (who assumed their observations of crop performance were too qualitative to be of worth/interest) and breeders (who thought that the traits identified by farmers as desirable were not worthwhile pursuing). The platform helped to challenge those initial assumptions. In Mexico, the participants' recognition that their own attitudes and actions were contributing to processes of cultural and ecological loss lead to innovations in what they considered potential future interventions, shifting their focus from an exclusive focus on the value of "eco-technologies" to a focus on community education and fostering participatory approaches with urban residents.

\section{Conclusions: reframing to address the cognitive locks-ins that resist transformative change}

In all of the Pathways hub initiatives, reframing processes, at multiple levels, were understood as a crucial element in addressing the lock-ins that can stand in the way of building alternative pathways to sustainability. This is because dominant ideas form part of the 'glue' that helps to bind the more material, institutional and political elements of established socio-technical-ecological systems together, in mutually dependent ways. Although reconfiguring such systems so as to support alternative pathways of change, is highly challenging, a route into trying to do so lies in shifting the ways in which people think about the problems those systems generate and the kinds of solutions that are possible and desirable. The innovation literature on niche technologies suggests that this is what entrepreneurs and activists trying to develop alternative technologies and practices do; when for example, they try and represent their innovations to, say, investors or policy-makers, as desirable solutions to problems generated by dominant systems (Raven et al. 2016).

Reframing processes, then, are trying to weaken or challenge what we can call cognitive lock-in or ideational path dependency; i.e., the largely unquestioned or unchallenged ways in which sustainability issues and problems are usually thought about. In different ways, all the Pathways hub initiatives were attempting to challenge and broaden the ways in which actors that are implicated in a system, in different ways, think about problems, their causes and how they imagine solutions and processes of change. In this way new sets of ideas may sometimes start to create political realignments or coalitions between actors, prompt recognition of novel policy options, highlight glossed over uncertainties 
or induce the production of new kinds of knowledge, thus beginning to challenge the logic that helps to reproduce incumbent system structures and practices

The alluring aspect of this is that while cognitive lock-in underpins problematic institutional, political and technological pathways of change, it is something that is amenable to challenge. Unlike the rigidities associated with particular established industrial structure, or physical infrastructure, the ways in which we - policy-makers, citizens, activists and others - collectively think about peoples' roles, their agency, the nature of problems and desired directions of change are amenable to being altered by a trans-disciplinary research process which pays attention to reframing.

\section{References}

Allouche, J., Middleton, C. and Gyawali, D. (2019). The Knowledge Nexus and Transdisciplinarity. In Chapter 4 Allouche, J. Middleton, C. and Gyawali, D. (eds.), The Water-Food-Energy Nexus. Abingdon: Routledge.

Cavicchi, B. and Ely, A. (2016). Bioenergy Pathways Framing and reframing sustainable bioenergy pathways: The case of Emilia Romagna. Available at: www.steps-centre. org/publications

Charli-Joseph, L., Siqueiros-García, J. M., Eakin, H., Manuel-Navarrete, D. and Shelton, R. (2018). Promoting agency for social-ecological transformation: a transformationlab in the Xochimilco social-ecological system. Ecology and Society, 23(2). doi:10.5751/ ES-10214-230246.

Eakin, H., Shelton, R. E., Siqueiros-García, J. M., Charli-Joseph, L. and ManuelNavarrete, D. (2019). Loss and social-ecological transformation: pathways of change in Xochimilco, Mexico. Ecology and Society, 24(3). doi:10.5751/ES-11030-240315.

Ely, A. and A. Marin (2016). Learning about 'Engaged Excellence' across a transformative knowledge network. IDS Bulletin 47(6), 73-86.

Ely, A. and Wach, E. (2018). Endings and beginnings: project-based work within wider transformations, STEPS Centre blog October 3 2018, https://steps-centre.org/blog/ endings-and-beginnings-project-based-work-within-wider-transformations/

Goffman, E. (1974). Frame Analysis: An Essay on the Organization of Experience. Cambridge, MA: Harvard University Press.

Hajer, M. (1995). The Politics of Environmental Discourse Ecological Modernization and the Policy Process. Oxford: Clarendon Press.

Laws, D. and Rein, M. (2003). Reframing practice. In Deliberative Policy Analysis. Cambridge University Press. pp. 172-206. doi:10.1017/CBO9780511490934.008.

Leach, M., Scoones, I. and Stirling, A. (2010a) Dynamic Sustainabilities: Technology, Environment, Social Justice. London: Earthscan.

Leach, M., Scoones, I. and Stirling, A. (2010b) Governing epidemics in an age of complexity: Narratives, politics and pathways to sustainability. Global Environmental Change, 20(3): 369-377. doi:10.1016/j.gloenvcha.2009.11.008.

Marshall, F., Dolley, J. and Priya, R. (2018). Transdisciplinary research as transformative space making for sustainability: Enhancing propoor transformative agency in Periurban contexts. Ecology and Society, 23(3). doi: 10.5751/ES-10249-230308.

Oberlack, C., Breu, T., Giger, M., et al. (2019). Theories of change in sustainability science. GAIA, 28: 106-111. doi:10.14512/gaia.28.2.8.

Page, G. G., Wise, R. M., Lindenfeld, L., Moug, P., Hodgson, A., Wyborn, C. and Fazey, I. (2016). Co-designing transformation research: Lessons learned from research on 
deliberate practices for transformation. Current Opinion in Environmental Sustainability, 20, 86-92. doi: 10.1016/j.cosust.2016.09.001.

Pahl-Wostl, C., Mostert, E. and Tábara, D. (2008). The growing importance of social learning in water resource management and sustainability science. Ecology and Society, 13(1), art. 24.

Pereira, L., Frantzeskaki, N., Hebinck, A., Charli-Joseph, L., Drimie, S., Dyer, M., Eakin, H., Galafassi, D., Karpouzoglou, T., Marshall, F., Moore, M.-L., Olsson, P., Siqueiros-García, J. M., Van Zwanenberg, P. and Vervoort, J. M. (2020). Transformative spaces in the making: Key lessons from nine cases in the Global South, Sustainability Science, 15, 161-178.

Randhawa, P. and Marshall, F. (2014). Policy transformations and translations: Lessons for sustainable water management in peri-urban Delhi, India. Environment and Planning C: Government and Policy. doi:10.1068/c10204.

Randhawa, P., Marshall, M., Kushwaha, P. and Desai, P. (2020). Pathways for sustainable urban waste management and reduced environmental health risks in India: Winners, losers and alternatives to Waste to Energy in Delhi. Frontiers in Sustainable Cities. doi: 10.3389/frsc.2020.00014.

Raven, R., Florian, K., Verhees, B. and Smith, A. (2016). Niche construction and empowerment through socio-political work. A meta-analysis of six low-carbon technology cases. Environmental Innovation and Societal Transitions, 18: 164-180. ISSN 2210-4224.

Roe, E. (1994). Narrative Policy Analysis: Theory and Practice. Durham: Duke University.

Ruizpalacios, B., Charli-Joseph, L., Eakin, H., Siqueiros-García, J. M., ManuelNavarrete, D. and Shelton, R. (2019). El Laboratorio de Transformación en el Sistema Socio-Ecológico de Xochimilco, Ciudad de México: Una guía metodológica. Ciudad de México. México: LANCIS-IE, UNAM.

Scoones, I., Stirling, A., Abrol, D., Atela, J., Charli-Joseph, L., Eakin, H., Ely, A., Olsson, P., Pereira, L., Priya, R., van Zwanenberg, P. and Yang, L. (2020). Transformations to sustainability: Combining structural, systemic and enabling approaches, Current Opinion in Environmental Sustainability, 42, 65-75.

Stirling, A., Leach, M., Mehta, L., Scoones, I., Smith, A., Stagl, S. and Thompson, J. (2007). Empowering designs: Towards more progressive appraisal of sustainability, STEPS Working Paper 3, Brighton: STEPS Centre.

Stirling, A. (2012). From sustainability; through diversity to transformation: Towards more reflexive governance of vulnerability. In Hommels, A., Mesman, J., and Bijker, W. E. (eds.) Vulnerability in Technological Cultures: New Directions in Research and Governance. Cambridge, MA, US: MIT Press, pp. 305-332.

Vogel, I. (2012). Review of the use of 'Theory of Change' in international development, (April).

Van Zwanenberg, P., Eakin, H., Turhan, E., Mukute, M. and Marshall, F. (2017). What does transformative research for sustainability look like? https://transformationsto sustainability.org/magazine/transformative-research-sustainability-look-like/

van Zwanenberg, P., Ely, A., Smith, A., et al. (2011). Regulatory harmonization and agricultural biotechnology in Argentina and China: Critical assessment of statecentered and decentered approaches. Regulation \& Governance, 5(2): 166-186. doi: 10.1111/j.1748-5991.2010.01096.x.

VanKerkhoff, L. and Szlezák, N. (2010). The role of innovative global institutions in linking knowledge and action. Proceedings of the National Academy of Sciences of the United States of America, 113(17): 4603-4608. doi:10.1073/pnas.0900541107.

Wittmayer, J. M. and Schäpke, N. (2014). Action, research and participation: Roles of researchers in sustainability transitions. Sustainability Science, 9(4): 483-496. 